\title{
How to use the "Biotechnology Directory of Eastern Europe"
}

The Directory is divided into the main directory and three additional indexes:

\section{Directory. Research Institutes, Universities, Companies and Organizations}

Entries are arranged alphabetically country by country whereby institutions are described in terms of their addresses and key executives, research activities, and their products and services.

\section{Alphabetical Index}

The alphabetical index lists all entries of the directory in alphabetical order and indicates the country under which the entry is registered.

\section{Subject Index}

All directory entries are classified according to field of research and product category. For each index entry the research institute, university or company working in this specific field and/or providing a specific product is listed, followed by the country under which the entry appears in the directory.

\section{Index to Culture Collections}

Culture collections are arranged alphabetically and are represented by the name of the institution followed by the country under which the institution appears in the directory. 
